\title{
Faktor Risiko pada Lama Rawat dan Luaran Pasien Perawatan di Unit Perawatan Intensif Anak RSUP Sanglah Denpasar
}

Silvia Sudarmadji, Dyah Kanya Wati, Lanang Sidiartha

Bagian Ilmu Kesehatan Anak Fakultas Kedokteran Universitas Udayana/RS Sanglah, Denpasar

Latar belakang. Penelitian yang menelaah hubungan faktor risiko jenis kelamin, usia, status gizi, pemakaian jenis terapi oksigen, dan pemberian sedini mungkin nutrisi enteral terhadap lama rawat dan luaran perawatan UPIA belum banyak dilakukan.

Tujuan. Menilai pengaruh faktor risiko jenis kelamin, usia, status gizi, pemakaian jenis terapi oksigen, pemberian nutrisi enteral dini terhadap lama rawat dan luaran mortalitas pasien.

Metode. Penelitian analitik observasional dengan rancang kohort prospektif dilakukan selama periode Mei sampai Juli 2015 terhadap 81 pasien usia 1 bulan sampai 12 tahun di rawat di UPIA RSUP Sanglah, Denpasar.

Hasil. Terdapat 59,3\% pasien laki-laki, $65,4 \%$ berusia $<5$ tahun, berstatus gizi buruk $6,2 \%$, pemakaian jenis terapi oksigen nasal kanula $51,9 \%$ dan $60,5 \%$ pemberian nutrisi enteral $<48$ jam. Faktor risiko status gizi dan pemakaian jenis terapi oksigen berbeda bermakna $(p<0,05)$ terhadap lama perawatan UPIA. Usia $<5$ tahun (RR 2,818; IK95\% 0,897-8,854), pemakaian jenis terapi oksigen $(\mathrm{p}<0,001)$, terutama jenis intubasi (RR 6,000; IK95\% 2,775-12,972) dan pemberian nutrisi enteral $\geq 48$ jam (RR 0,003; IK95\% 1,406-7,830) merupakan faktor risiko terhadap luaran perawatan UPIA, tetapi hanya faktor risiko pengunaan terapi oksigen, terutama jenis intubasi berperan dan berisiko luaran meninggal 16,576 kali terhadap pasien (RR:16,576; IK95\% 2,688-102,225).

Kesimpulan. Faktor risiko status gizi dan pemakaian alat oksigenasi memperpanjang durasi lama rawat. Usia $<5$ tahun, pemakaian alat oksigenasi, dan waktu asupan nutrisi $\geq 48$ jam terbukti meningkatkan faktor risiko mortalitas. Sari Pediatri 2016; 17(6):455-62.

Kata kunci: lama perawatan, luaran perawatan, faktor risiko

\section{Risk Factors Related to Duration of stay and Mortality Outcome in Pediatric Intensive Care Unit of Sanglah Hospital, Denpasar, Bali, Indonesia}

Silvia Sudarmadji, Dyah Kanya Wati, Lanang Sidiartha

Background. Studies that examine association between various risk factors such as sex, age, nutritional status, oxygen therapy and enteral nutrition in relation with duration of stay and mortality outcome in pediatric intensive care unit are still rare.

Objective. This study is aims to identify the risk factors (sex, age, nutritional status, different types of oxygen therapy and enteral nutrition) affecting duration of stay and mortality outcome.

Methods. A prospective cohort study of 81 children admitted to Pediatric Intensive Care Unit Sanglah hospital, aged 1 month until 12 years from May to July 2015 was conducted.

Results. Based on characteristic data of study, there were $59.3 \%$ male, $65.4 \%$ under 5 years old, 6,2\% with severe malnutrition, $51.9 \%$ patients with nasal cannula and $60.5 \%$ with enteral nutrition less than 48 hours. Risk factors observed were nutritional status and patients that received oxygen therapy were associated with longer duration of stay $(\mathrm{p}<0.05)$. Several other risk factors that were related to mortality outcome were age under five years (RR 2.818; 95\% CI 0.897-8.854), oxygen therapy ( $<<0,001)$ intubation type (RR 6.000; 95\% CI 2.775-12.972) and enteral nutrition more than 48 hours (RR 0.003; 95\% CI 1.406-7.830), however only risk factor that increase mortality outcome upto 16.57 times was oxygen therapy especially if it was given through intubation (RR 16.576; 95\% CI 2.688-102.225) in PICU Sanglah hospital, Denpasar.

Conclusions. Nutritional status and oxygen therapy were associated with prolonged length of stay. Age under 5 years, oxygen therapy, and enteral nutritional more than 48 hours increase mortality outcome of patients. Sari Pediatri 2016; 17(6):455-62.

Keywords: length of stay, mortality outcome, risk factor

\footnotetext{
Alamat korespondensi: Dr.Silvia Sudarmadji. Bagian Ilmu Kesehatan Anak, Fakultas Kedokteran Universitas Udayana, RSUP Sanglah Denpasar. Jl. Pulau Nias 80114. Tel./Fax. +62-361 244038 atau +62-361 257387 atau 081-384-425-148. E-mail : Sylviasudarmadji@yahoo.com
} 
U nit Perawatan Intensif Anak (UPIA) adalah unit tersendiri di dalam rumah sakit yang menangani pasien kritis karena penyakit, trauma atau komplikasi penyakit lain, dan perawatan pasca pembedahan besar. Perawatan UPIA memfokuskan diri dalam bidang life support atau organ supportyang kerap membutuhkan pemantauan intensif. ${ }^{1}$

Mortalitas dan lama rawat pasien anak di UPIA sangat tinggi, dipengaruhi beberapa variabel faktor risiko. Beberapa faktor yang berperan terhadap lama perawatan dan luaran pasien di UPIA, antara lain faktor usia, faktor penjamu, agent penyebab infeksi, status gizi, pemakaian alat bantu pernapasan, serta tata laksana kegawatan efektif di UPIA. ${ }^{2}$

Angka kematian pasien di UPIA di Amerika sekitar $20 \%$ pasien (1 dari 5 atau setara 500000 anak dirawat di UPIA pertahun), sedangkan angka kematian di UPIA di seluruh dunia sekitar $25 \%$ pertahun. ${ }^{3}$ Angka mortalitas pasien anak dirawat di UPIA akibat infeksi 24\%-52\%, lama rawat 7 hari, dengan penanganan yang adekuat, dan $50 \%$ secara bermakna berhubungan dengan kematian. ${ }^{4}$

Berdasarkan usia, umur anak kurang dari 5 tahun memiliki risiko meninggal 0,6 kali dibandingkan dengan kelompok lebih dari 5 tahun dan status gizi buruk memiliki risiko meninggal 9,43 kali dibandingkan status gizi baik atau kurang. ${ }^{5}$ Masa rawat dipengaruhi oleh faktor usia, komorbiditas, hipermetabolisme, kegagalan organ, serta defisiensi nutrisi. ${ }^{6}$

Pada setiap pasien rawat UPIA, terapi nutrisi telah menjadi perhatian. Intervensi nutrisi sejak awal rawat dipercaya memengaruhi luaran klinis jangka panjang pasien. ${ }^{7-8}$ Dukungan nutrisi enteral sejak dini di ruang intensif memperbaiki luaran klinis pasien. ${ }^{9}$ Pada pasien kritis, rute enteral direkomendasikan segera diberikan karena mencegah atrofi mukosa, menjaga flora normal usus, menjaga sistem enzim enterohepatik, menurunkan angka kematian, dan pemakaian lama ventilator. Target pemberian kalori kebutuhan critical iil tercapai pada hari perawatan keempat di UPIA. ${ }^{10}$

Beberapa penelitian di negara maju menemukan hubungan status gizi buruk dengan lama rawat yang bertambah, kualitas hidup yang turun, dan peningkatan morbiditas maupun mortalitas di rumah sakit. ${ }^{11-12}$ Risiko malnutrisi rawat inap meningkat 3,69 kali apabila anak dirawat lebih dari seminggu dan tidak ada hubungan antara diagnosis awal penyakit dengan insidens malnutrisi rawat inap. ${ }^{13}$
Penelitian mengkritisi faktor risiko berupa jenis kelamin, usia, status nutrisi, jenis alat terapi oksigen, pemberian nutrisi oral dini terhadap lama rawat dan luaran perawatan pasien UPIA belum banyak dilakukan di Indonesia. Berdasarkan latar belakang ini, peneliti bermaksud melakukan penelitian mengenai hubungan faktor risiko terhadap lama rawat dan luaran pasien di UPIA RSUP Sanglah Denpasar.

\section{Metode}

Penelitian kohort prospektif terhadap pasien usia 1 bulan sampai 12 tahun diikuti selama perawatan di UPIA RSUP Sanglah Denpasar periode Mei 2015 sampai Juli 2015. Data subyek diambil saat masuk dan selama perawatan. Dilakukan pengamatan langsung terhadap usia anak, status nutrisi anak, jenis pemakaian alat terapi oksigen, waktu mulai pemberian nutrisi oral, tehadap lama rawat, dan luaran pasien.

Besar sampel dihitung berdasarkan perkiraan proporsi dari laporan $49,1 \%$, dengan penetapan presisi $10 \%$, tingkat kemaknaan $\alpha<0,05$ dan power penelitian $80 \%$ maka didapatkan besar sampel minimal 81 pasien. ${ }^{14}$ Penelitian telah mendapat ijin dari komite etik Fakultas Kedokteran Universitas Udayana. Semua data dikumpulkan diproses dengan bantuan program komputer dengan menggunakan software statistik SPSS 17.0.

Sampel adalah semua pasien usia 1 bulan sampai 12 tahun dan diambil secara konsekutif. Kriteria inklusi adalah semua pasien usia 1 bulan sampai 12 tahun yang menjalani rawat inap di UPIA RSUP Sanglah yang bersedia mengikuti penelitian dan menandatangani lembar persetujuan setelah penjelasan (PSP). Kriteria eksklusi adalah pasien dengan lama rawat di UPIA $<24$ jam dan data kuesioner tidak lengkap.

Usia adalah satuan waktu yang diukur dari tanggal, bulan, dan tahun anak dilahirkan. Pengukuran antropometri dilakukan sesuai dengan prosedur tetap Bagian Ilmu Kesehatan Anak RSUP Sanglah Denpasar. Status nutrisi menggunakan indikator berat badan per tinggi badan dengan menggunakan program WHO Anthro dan WHO AnthroPlus berdasarkan standar baku antropometri WHO tahun 2006 dan Asuhan Nutrisi Pediatrik (pediatric nutrition care) Rekomendasi Unit Kerja Koordinasi (UKK) Nutrisi dan Penyakit Metabolik IDAI tahun 2011. ${ }^{15-17}$ 
Oksigenasi adalah pemenuhan kebutuhan oksigen dalam tubuh dengan cara melancarkan saluran masuknya oksigen atau memberikan aliran gas oksigen sehingga konsentrasi oksigen dalam tubuh meningkat. Jenis oksigenasi pasien dicatat saat masuk UPIA dan dikelompokkan kembali menjadi terapi oksigen yang diberikan melalui non invasive respiratory support dan invasive respiratory support. Terapi nutrisi enteral dilakukan oleh dokter yang merawat pasien sesuai dengan standar prosedur tetap Bagian Nutrisi dan Penyakit Metabolik Bagian/SMF Ilmu Kesehatan Anak RSUP Sanglah Denpasar. Terapi nutrisi enteral dapat berupa oral dan per nasogastric tube. Waktu mulai pemberian nutrisi enteral dikelompokkan menjadi pemberian nutrisi oral $<48$ jam dan $\geq 48$ jam. Lama rawat adalah waktu yang dibutuhkan untuk penanganan dan perawatan pasien anak sesuai dengan standar pelayanan UPIA yang ada di RSUP Sanglah Denpasar. Lama rawat dihitung dalam hari, berdasarkan selisih antara tanggal masuk rawat di UPIA dan tanggal pindah ke ruangan rawat bangsal. Luaran adalah hasil akhir (hidup atau meninggal) paska perawatan UPIA.

\section{Hasil}

Selama periode penelitian didapatkan 147 pasien bayi atau anak dalam perawatan UPIA bulan Mei 2015 sampai Juli 2015, 81 pasien dianalisis, 66 dieksklusi, dan 36 pasien meninggal kurang dari 24 jam perawatan UPIA, 2 pasien meninggal saat tindakan operasi paska perawatan 48 jam, 2 pasien berusia $>12$ tahun, dan 26 pasien data tidak lengkap. Data karakteristik demografi subjek tertera pada Tabel 1.

Penelitian dilakukan terhadap 81 pasien yang dirawat dan memenuhi kriteria dari bulan Mei- Juli 2015. Subjek anak berjenis kelamin laki laki (59,3\%) dan perempuan $(40,7 \%)$. Kelompok berisiko berusia di bawah 5 tahun $(65,4 \%)$. Kasus terbanyak dirawat non bedah $85,2 \%$, sedangkan bedah $14,8 \%$. Subjek dengan gizi buruk $(6,2 \%)$, kurang $(28,4 \%)$, baik $(54,3 \%)$, lebih $(2,5 \%)$, dan obesitas $(8,6 \%)$. Pemakaian alat bantu pernapasan yang banyak digunakan adalah nasal kanula $(51,9 \%)$ dan waktu pemberian awal nutrisi oral banyak dimulai pada waktu <48 jam $(60,5 \%)$. Luaran hidup yang didapatkan $62(76,5 \%)$ dan yang meninggal $19(23,5 \%)$ anak.

Analisis median terhadap lama perawatan pada faktor risiko, terdapat hubungan bermakna antara lama
Tabel 1. Karakteristik pasien

\begin{tabular}{lcc}
\hline Karakteristik subjek $(\mathrm{n}=81)$ & $\mathrm{N}$ & $\%$ \\
\hline Jenis kelamin & & \\
$\quad$ Laki-laki & 48 & 59,3 \\
$\quad$ Perempuan & 33 & 40,7 \\
Usia(tahun) & & \\
$\quad 5$ & 53 & 65,4 \\
$\quad 5$ & 28 & 34,6 \\
Status gizi & & \\
$\quad$ Buruk & 5 & 6,2 \\
Kurang & 23 & 28,4 \\
Baik & 44 & 54,3 \\
Lebih & 2 & 2,5 \\
Obesitas & 7 & 8,6 \\
Jenis kasus & & \\
Bedah & 12 & 14,8 \\
$\quad$ Non bedah & 69 & 85,2 \\
Jenis terapi oksigen & & \\
$\quad \mathrm{O}_{2}$ nasal kanula & 42 & 51,9 \\
O sungkup & 12 & 14,8 \\
CPAP & 9 & 11,1 \\
$\quad$ Ventilator & 18 & 22,2 \\
Pemberian nutrisi oral (jam) & & \\
$\quad \geq 48$ & 32 & 39,5 \\
$\quad<48$ & 49 & 60,5 \\
Luaran & & \\
Meninggal & 19 & 23,5 \\
Hidup & 62 & 76,5 \\
\hline
\end{tabular}

perawatan terhadap status gizi $(\mathrm{p}=0,009)$ dan jenis terapi oksigen $(p=0,029)$ memiliki median lama rawat lebih dari 7 hari. Kelompok jenis kelamin $(\mathrm{p}=0,621)$, usia pasien $(\mathrm{p}=0,858)$, dan waktu pemberian nutrisi oral $(\mathrm{p}=0,253)$ secara statistik tidak bermakna signifikan terhadap durasi lama perawatan di UPIA RSUP Sanglah, Denpasar (Tabel 2).

Hasil luaran meninggal selama perawatan di UPIA terhadap faktor risiko berdasarkan uji statistik pada Tabel 3, didapatkan hubungan faktor risiko usia kurang dari 5 tahun (RR 2,818; IK95\% 0,897-8,854), penggunaan jenis terapi oksigen $(\mathrm{p}<0,001)$ terutama jenis terapi intubasi (RR 6,000; IK95\% 2,775-12,972 ) dan waktu asupan permulaan nutrisi oral $\geq 48$ jam (RR 0,003; IK95\% 1,406-7,830).

Berdasarkan uji statistik pada Tabel 4, uji regresi logistik menggunakan metode backward, menunjukkan faktor risiko terapi oksigen terutama jenis intubasi yang paling memengaruhi luaran 16,57 kali meninggal di UPIA RSUP Sanglah $(\mathrm{p}<0,05)$. 
Tabel 2. Hasil analisis bivariat faktor risiko terhadap lama perawatan

\begin{tabular}{lcc}
\hline Variabel & Median lama rawat (min - max) & $\mathrm{p}$ \\
\hline Jenis kelamin & & \\
$\quad$ Laki-laki & $5(2-35)$ & $0,858^{\mathrm{a}}$ \\
$\quad$ Perempuan & $6(2-21)$ & \\
Usia (tahun) & & \\
$\quad<5$ & $6(2-21)$ & $0,621^{\mathrm{a}}$ \\
$\geq 5$ & $5(2-35)$ & \\
Status gizi & & $0,009^{* \mathrm{~b}}$ \\
$\quad$ Buruk-kurang & $7(3-19)$ & \\
Baik & $5(2-35)$ & \\
Lebih-obesitas & $4(2-7)$ & \\
Jenis terapi oksigen & & \\
$\mathrm{O}_{2}$ nasal kanula & $4(2-35)$ & \\
$\mathrm{O}_{2}$ sungkup & $4(2-17)$ & \\
CPAP & $7(5-18)$ & \\
$\quad$ Ventilator & $7(2-19)$ & \\
Pemberian nutrisi oral (jam) & & \\
$\geq 48$ & $6(2-18)$ & \\
$<48$ & $5(2-35)$ & \\
\hline
\end{tabular}

Keterangan: *bermakna $\mathrm{p}<0,05, \mathrm{p}=$ probabilitas a:Uji Mann Withney

b:Uji Kruskal-Wallis

Tabel 3. Analisis bivariat antara faktor risiko terhadap luaran perawatan

\begin{tabular}{|c|c|c|c|c|c|}
\hline Variabel & $\begin{array}{c}\text { Meninggal } \\
\mathrm{n}(\%)\end{array}$ & $\begin{array}{c}\text { Hidup } \\
\mathrm{n}(\%)\end{array}$ & RR & $\mathrm{p}$ & IK95\% \\
\hline \multicolumn{6}{|l|}{ Jenis kelamin } \\
\hline Laki-laki & $11(22,9)$ & $37(77,1)$ & 0,945 & 0,890 & $0,427-2,095$ \\
\hline Perempuan & $8(23,5)$ & $25(75,8)$ & & & \\
\hline \multicolumn{6}{|l|}{ Usia (tahun) } \\
\hline$<5$ & $16(30,2)$ & $37(69,8)$ & 2,818 & $0,049^{*}$ & $0,897-8,854$ \\
\hline$\geq 5$ & $3(10,7)$ & $25(89,3)$ & & & \\
\hline \multicolumn{6}{|l|}{ Status gizi } \\
\hline Buruk-kurang & $8(28,6)$ & $20(71,4)$ & - & 0,199 & - \\
\hline Baik & $11(25,0)$ & $33(75,0)$ & & & \\
\hline Lebih-obesitas & $0(0)$ & $9(100)$ & & & \\
\hline \multicolumn{6}{|l|}{ Jenis terapi oksigen } \\
\hline $\mathrm{O}_{2}$ nasal kanula & $3(7,1)$ & $39(92,9)$ & ref & $<0,001^{*}$ & - \\
\hline $\mathrm{O}_{2}^{2}$ sungkup & $2(16,7)$ & $10(83,3)$ & 2,400 & & \\
\hline CPAP & $2(22,2)$ & $7(77,8)$ & 3,200 & & \\
\hline Ventilator & $12(66,7)$ & $6(33,3)$ & 9,400 & & \\
\hline \multicolumn{6}{|l|}{ Jenis terapi oksigen } \\
\hline Intubasi & $12(66,7)$ & $6(33,3)$ & 6,000 & $<0,001^{*}$ & $2,775-12,972$ \\
\hline Non-intubasi & $7(11,1)$ & $56(88,9)$ & & & \\
\hline \multicolumn{6}{|c|}{ Waktu pemberian nutrisi oral (jam) } \\
\hline$\geq 48$ & $13(40,6)$ & $19(59,4)$ & 3,318 & $0,003^{*}$ & $1,406-7,830$ \\
\hline$<48$ & $6(12,2)$ & $43(87,8)$ & & & \\
\hline
\end{tabular}

Keterangan: *bermakna, p<0,05; RR: risiko relatif; p:probabilitas; IK: interval kepercayaan hasil chi square test 
Silvia Sudarmadji dkk: Faktor Risiko pada lama rawat dan luaran pasien perawatan

Tabel 4. Analisis multivariat faktor risiko terhadap luaran mortalitas perawatan UPIA

\begin{tabular}{lcccc}
\hline Variabel & $\mathrm{B}$ & P value & OR & IK95\% \\
\hline Usia & 1,397 & 0,920 & 4,042 & $0,796-20,516$ \\
Status gizi & 2,877 & 0,990 & 17,756 & $4,630-21,366$ \\
Jenis terapi oksigen & 2,808 & $0,002^{*}$ & 16,576 & $2,688-102.225$ \\
Waktu pemberian nutrisi oral & 0,047 & 0,916 & 1,048 & $0,434-2,535$ \\
\hline
\end{tabular}

Keterangan: *bermakna, p<0,05; OR: Odd Ratio; p:probabilitas; IK: interval kepercayaan hasil logistik regresi

\section{Pembahasan}

Penelitian kami menggambarkan persentase pasien anak lama rawat lebih banyak berjenis kelamin lakilaki (59,3\%). Tidak terdapat perbedaan terhadap lama rawat dan luaran kejadian meninggal. Hal tersebut sejalan dengan hasil yang diperoleh Arceci $\mathrm{dkk}^{18}$ yang melaporkan tidak ada perbedaan antara jenis kelamin dengan lama rawat dan luaran meninggal.

Usia terbanyak usia di bawah 5 tahun $(65,4 \%)$. Hasil penelitian kami serupa dengan laporan Irene $\mathrm{dkk}^{19}$ yang melaporkan hasil terbanyak usia di bawah 5 tahun $(60 \%)$ perawatan pasien di UPIA. Secara garis besar, dari berbagai penelitian yang telah dilakukan dengan kriteria pasien umur 1 bulan sampai 18 tahun, pasien berusia di bawah 5 tahun paling banyak dirawat di ruangan intensif dengan pertimbangan sebagian besar sistem imun pejamu belum matur. Tahap perkembangan sistem imun menunjukkan bahwa semakin muda usia, semakin sedikit tingkat kematangan sistem imun yang telah dicapai. Dengan demikian, semakin rendah kemampuan eradikasi patogen dapat meningkatkan risiko kematian pada anak dengan usia muda.

Kami mendapatkan hubungan antara status gizi terhadap lama rawat dan hubungan tidak bermakna antara status gizi terhadap luaran mortalitas perawatan UPIA. Keadaan malnutrisi dapat meningkatkan kerentanan pejamu terhadap penyakit kritis, terutama pada anak, serta menimbulkan keadaan imunodefisiensi sekunder. Pasien yang memerlukan perawatan UPIA lebih lama karena stres metabolik dan infeksi berat sendiri dapat mengakibatkan kejadian malnutrisi lebih berat, terutama pada status gizi buruk akibat peningkatan upaya kompensasi metabolisme tubuh pada keadaan kritis.

Mehta $\mathrm{dkk},{ }^{20}$ dalam penelitian secara multisenter pada 31 UPIA rumah sakit pendidikan, melaporkan bahwa malnutrisi berat telah terjadi pada 30\% pasien.
Prevalensi malnutrisi yang tinggi sejak awal masuk UPIA Anak FKUI RSCM berhubungan dengan tingkat ekonomi masyarakat Indonesia. Wahyuni $\mathrm{dkk}^{21}$ melaporkan 96 pasien anak usia 6-60 bulan dengan penyakit infeksi dan non infeksi di RSUD Pekanbaru. Pasien dengan status gizi awal tidak baik mempunyai risiko 2,52-3,24 kali lebih tinggi untuk menjalani lama rawat lebih panjang dibandingkan subjek dengan gizi awal baik. Semakin buruk status gizi, semakin tinggi risiko untuk menjalani rawat inap yang lebih panjang. Keadaan malnutrisi pada anak berhubungan dengan berbagai perubahan fisiologis, ketidakseimbangan mikronutrien, disfungsi gastrointestinal, penurunan fungsi imunitas selular, penurunan fungsi fagositosis, dan sistem komplemen. Derajat penyakit dapat memperberat keadaan malnutrisi yang sudah ada sebelumnya dan menjadi faktor predisposisi terjadinya komplikasi penyakit. Hal tersebut menyebabkan pasien sakit kritis, mengakibatkan hari perawatan menjadi lebih panjang.

Kami menemukan perbedaan banyaknya pasien berstatus gizi baik yang dirawat di UPIA RSUP Sanglah $(54,3 \%)$, berbeda dibandingkan laporan penelitian sebelumnya. De Neef $\mathrm{dkk}^{22}$ melaporkan bahwa status gizi terbanyak pasien saat awal masuk UPIA adalah gizi kurang $(48,9 \%)$ dan saat masuk UPIA 15\%-25\% kasus sudah mengalami malnutrisi. Prevalensi status gizi baik lebih banyak dikarenakan RSUP Sanglah merupakan rumah sakit pusat rujukan tersier. Rumah sakit rujukan untuk pasien yang tidak dapat ditangani oleh rumah sakit lain. Di samping itu, RSUP Sanglah memiliki standar syarat klasifikasi yang spesifik (indikasi perawatan UPIA) terhadap pasien yang layak mendapatkan perawatan UPIA.

Lama rawat dalam rentang 2 sampai 35 hari disebabkan variasi pasien anak berupa leukemia dengan hiperleukositosis, ketidakstabilan paska bedah dan komplikasi, penelusuran penyebab penyakit autoimun disorder, seperti SLE, dan sepsis berat yang 
membutuhkan pemantauan ketat lebih lama. Terdapat perbedaan antara lama rawat terhadap status gizi dan pemakaian jenis terapi oksigen. Kelompok risiko status gizi malnutrisi (gizi buruk dan kurang) dan pemakaian ventilator memiliki median lama rawat lebih dari 7 hari dibandingkan variabel risiko lainnya.

Pemberian nutrisi oral terbanyak dimulai pada hari ke dua $(60,5 \%)$. Hal tersebut terjadi karena tata laksana awal perawatan yang adekuat terhadap pasien di UPIA RSUP Sanglah. Prioritas utama adalah menjaga stabilitas susunan saraf pusat, respirasi, kardiovaskular, metabolik, dan hematologi. Pemberian nutrisi enteral sedini mungkin diberikan jika semua keadaan tersebut telah stabil. Pemberian nutrisi enteral setelah $\geq 48$ jam $(39,5 \%)$ perawatan dilakukan karena pasien memerlukan waktu stabilisasi lebih lama. Rekomendasi ASPEN (American Society for parenteral and enteral nutrition) menyebutkan bahwa apabila tidak ada gangguan saluran cerna, pemberian nutrisi enteral harus diberikan sesegera mungkin. Stabilisasi pasien critical ill kadang tidak mudah sehingga memerlukan waktu lebih lama untuk memulai pemberian nutrisi. Pemberian nutrisi oral yang lebih lama ( $\geq 48$ jam) dapat memengaruhi luaran meninggal pasien anak yang dirawat di UPIA sebesar 3,32 kali, tetapi tidak memengaruhi durasi lama rawat pasien. ${ }^{23}$

Terdapat hubungan antara usia, jenis pemakaian terapi oksigen intubasi (ventilator), dan waktu pemberian nutrisi oral lebih dari 48 jam terhadap mortalitas pasien rawat. Pada kelompok usia kurang dari 5 tahun, risiko mortalitas meningkat 2,82 kali dibandingkan usia di atas 5 tahun pada analisis bivariat. Pada penelitian kami, keadaan malnutrisi, terutama gizi buruk dan gizi kurang, tidak berisiko meningkatkan mortalitas karena penyebaran subjek berdasarkan status gizi tidak merata mewakili setiap status gizi. Pejamu rentan terhadap penyakit akibat malnutrisi. Infeksi juga dapat memperberat kejadian malnutrisi, terutama gizi buruk akibat peningkatan metabolisme pada keadaan kritis. ${ }^{24}$ Penelitian kami sesuai dengan Villegas $\mathrm{dkk}^{25}$ yang melaporkan bahwa anak malnutrisi (gizi kurang dan buruk) lebih banyak $(49,1 \%)$ meninggal dibandingkan dengan yang bertahan hidup (35,5\%). Demikian pula Metta ${ }^{20} \mathrm{dkk}$ yang melaporkan 6 pasien malnutrisi berat dari 11 subjek meninggal vs 3 malnutrisi berat dari 21 subjek hidup. Pada keadaan kritis, karena adanya disfungsi saluran cerna pasien sulit mendapatkan nutrisi enteral pada 48 jam pertama, intoleransi minum, resusitasi berkepanjangan, retriksi cairan, tindakan invasif atau rendahnya prioritas terapi nutrisi juga mengakibatkan asupan kalori rendah. Pemberian nutrisi inadekuat tersebut meningkatkan risiko infeksi, lama rawat inap, lama pemakaian antibiotik, lama penggunaan ventilasi mekanik, dan mortalitas. Pemantauan lebih lanjut, jenis terapi oksigen berhubungan antara lebih lama durasi rawat sebesar 0,03 kali dan luaran meninggal sebesar 6 kali.

Beberapa keterbatasan penelitian adalah penyebaran distribusi subjek penelitian terhadap faktor risiko tidak terdistribusi merata sehingga diperlukan lanjutan dengan jumlah subjek yang lebih besar. Faktor risiko yang dijadikan penelitian belum melibatkan penyakit dasar terhadap subjek penelitian yang dirawat di UPIA RSUP Sanglah, Denpasar. Alat baku pengukuran khusus antropometri subjek dalam keadaan khusus dan kegawatan belum tersedia sehingga antropometri dan status gizi pasien selama perawatan di UPIA dapat diukur secara objektif dan asupan kalori nutrisi enteral dapat adekuat sesuai dengan target kebutuhan kalori yang dibutuhkan berdasarkan kebutuhan nutrisi pasien kritis. Tata laksana kegawatan yang adekuat pada awal perawatan di UPIA, perhatian khusus pada perawatan pasien di bawah usia 5 tahun dan keadaan status gizi, seleksi ketat indikasi penggunaan dan persingkat pemakaian ventilator sesuai klinis pasien, serta intervensi nutrisi enteral diberikan lebih awal dan segera mungkin terhadap pasien selama perawatan setelah penilaian objektif keadaan umum pasien tersebut stabil.

\section{Kesimpulan}

Status gizi dan pemakaian alat oksigenasi memperpanjang lama rawat. Faktor risiko usia di bawah 5 tahun, pemakaian alat oksigenasi, dan waktu asupan nutrisi lebih dari 48 jam terbukti meningkatkan mortalitas pada pasien anak perawatan di UPIA RSUP Sanglah, hanya pemakaian alat oksigenasi terutama jenis intubasi (ventilator) memiliki hubungan bermakna terhadap luaran mortalitas perawatan UPIA.

\section{Daftar pustaka}

1. Shime N, Kawasaki T, Saito O, Akamine Y, Toda $\mathrm{Y}$, Takeuchi M. Incidence and risk factors for 
mortality in paediatric severe sepsis: results from the national paediatric intensive care registry in Japan. Intensive Care Med 2012;12:25-32.

2. Pollack MM, Ruttimann UE, Wiley JS. Nutritional depletions in critically ill children: associations with physiologic instability and increased quantity of care. JPEN J Parenter Enteral Nutr 1985;9:309-13.

3. Stratton RJ, King CL, Stroud MA. "Malnutrition Universal Screening Tool" predicts mortality and length of hospital stay in acutely ill elderly. $\mathrm{Br} \mathrm{J}$ Nutrition 2006;95: 325-30.

4. Amar W, Hadinegoro SR. Infeksi bakteri gram negatif di ICU anak:epidemiologi managemen antibiotik dan pencegahan. Sari Pediatri 2004;329 .

5. Desy D, Antonius HP, Mulyadi M, Bambang S. Faktor risiko yang berperan pada mortalitas sepsis. Sari Pediatri 2014;15;281-8.

6. Fina M, Julistio D, Herry G. Status gizi berdasarkan subjective global assessment sebagai faktor yang mempengaruhi lama perawatan pasien rawat inap anak. Sari Pediatri 2010;12:162-7.

7. Wakahara T, Shiraki M, Murase K. Nutritional screening with Subjective Global Assessment predicts hospital stay in patients with digestive diseases. Nutrition 2007;23:634-9.

8. Sorensen J, Kondrup J, Prokopowicz J. EuroOOPS: an international, multicentre study to implement nutritional risk screening and evaluate clinical outcome. Clinical Nutrition 2008;27:340-9.

9. Geila AR, Rocha EJM, Martins CV. The effects of hospitalization on the nutritional status of children. J Pediatr (Rio J) 2006;82:70-4.

10. Barr J, Hecht M, Flavin K,E, Khorana A, Gould MK. Outcomes in critically ill patients before and after the implementation of an evidencebased nutritional management protocol. Chest 2004;125:1446-57.

11. Jones NE, Dhaliwal R, Day AG, Ouellette-Kuntz $\mathrm{H}$, Heyland DK. Factors predicting adherence to the canadian clinical practice guidelines for nutrition support in mechanically ventilated, critically ill adult patients. J Crit Care 2008;23:301-7.

12. Kim H, Stotts NA, Froelicher ES, Engler MM, Porter C. Why patients in critical care do not receive adequate enteral nutrition? A review of the literature. J Crit Care 2012;27:702-13.

13. Sidiartha IGL. Insidens malnutrisi rawat inap pada anak balita di Rumah Sakit Umum Pusat Sanglah
Denpasar. Sari Pediatri 2008;9:381-5.

14. Madiyono B, Moeslichan S, Sastroasmoro S, Budiman I, Purwanto SH. Perkiraan besar sampel. Dalam: Sastroasmoro S \& Ismael $S$, penyunting. Dasar-dasar metodologi penelitian klinis. Jakarta:Sagung Seto;2008.h.302-31.

15. World Health Organization. WHO Anthro 2005 software for assessing growth and development of the world's children. Department of Nutrition for Health and Development. Geneva, Switzerland. 2006.

16. De Onis M, Onyango AW, Borghi E, Garza C, Yang $\mathrm{H}$. Comparison of the World Health Organization (WHO) child growth standards and the national center for health statistics/WHO international growth reference implications for child health programs. Pub Health Nutr 2006;9:942-7.

17. Sjarif D, Nasar S,Devaera Y, Tanjung C. Asuhan nutrisi pediatrik (Pediatric Nutrition Care). Rekomendasi Ikatan Dokter Anak Indonesia. Jakarta: UKK Nutrisi dan Penyakit Metabolik; 2011.h.1-14.

18. Arceci RJ, Hann IM, Smith OP. Platelet function disoders. Pediatric Hematology. Third Edition. 2006.

19. Irene Y, Abdul L, Yoga D, Suci F. Pemberian nutrisi pada pasien dengan penyakit kritis di ruang perawatan intensif anak rs cipto mangunkusumo. Sari Pediatri 2014;16:254-9.

20. Metta D, Soebardja D, Soemasetia DH. The use of Pediatric Logistic Organ Dysfunction (PELOD) scoring system to determine the prognosis of patients in pediatric intensive care units. Pediatr Indones 2006;46:1-6.

21. Wahyuni S, Julia M, Budiningsari RD. Pengukuran status gizi pasian anak menggunakan metode subjective global assessment sebagai prediktor lama rawat inap, status pulang dan kejadian malnutrisi di rumah sakit. Indonesian J Clin Nutrit 2005;2:28-3.

22. De Neef M, Geukers VGM, Dral A, Lindeboom R, Sauerwein HP, Bos AP. Nutritional goal prescriptionand delivery in a pediatric intensive care unit. Clin Nutr 2008;27:65-71.

23. A.S.P.E.N. Guidelines for the provision and assessment of nutrition support therapy in the adult critically ill patient: Society of Critical Care (SCCM) and American Society of Parenteral and Enteral Nutrition (A.S.P.E.N). JPEN J Parenter Enteral Nutr 2009;33:277-316. 
24. Leite HP, Isatugo MK, Sawaki L, et al. Anthropometric nutritional assessment of critically ill hospitalized children. Rev Paul Medicine1993;111:309-13.
25. Villegas D, Echandia CA. Factors associated with mortality through sepsis syndrome in children 31 days to 14 years of age. Colomb Med 2010;41:34957. 